\begin{tabular}{|c|c|c|c|}
\hline George Dimeling, MD & Laurice Bakaeen, PharmD & Jaikirshan Khatri, MD & Faisal G. Bakaeen, MD, FACS \\
\hline Department of Thoracic and Cardiovascular & Department of Pharmacy, Marymount & Department of Cardiovascular Medicine, & Director, Coronary Revascularization Center, \\
\hline Surgery, Heart, Vascular, and Thoracic & Hospital, Cleveland Clinic Health System, & Heart, Vascular, and Thoracic Institute, & Sheikh Hamdan bin Rashid Al Maktoum \\
\hline Institute, Cleveland Clinic, Cleveland, $\mathrm{OH}$ & Cleveland, $\mathrm{OH}$ & $\begin{array}{l}\text { Cleveland Clinic, Cleveland, } \mathrm{OH} \text {; Clinical } \\
\text { Assistant Professor, Cleveland Clinic } \\
\text { Lerner College of Medicine of Case Western } \\
\text { Reserve University, Cleveland, OH }\end{array}$ & $\begin{array}{l}\text { Distinguished Chair, Department of Thoracic } \\
\text { and Cardiovascular Surgery, Heart, Vascular, } \\
\text { and Thoracic Institute, Cleveland Clinic, } \\
\text { Cleveland, } \mathrm{OH} \text {; Professor, Cleveland Clinic } \\
\text { Lerner College of Medicine of Case Western } \\
\text { Reserve University, Cleveland, OH }\end{array}$ \\
\hline
\end{tabular}

\title{
CABG: When, why, and how?
}

\section{ABSTRACT}

Coronary revascularization has matured as a field since coronary artery bypass grafting (CABG) was first developed over 50 years ago, with diagnostic and treatment methods having advanced dramatically. CABG remains the standard of care for obstructive coronary artery disease, particularly for patients with multivessel disease or diabetes. It is now recognized that not all CABG is created equal-operative strategy, including conduit choice for bypass grafts and target coronary selection, affects survival. A multidisciplinary approach including surgeons with a special interest in CABG is recommended to optimize treatment selection and outcomes.

\section{KEY POINTS}

The main criteria guiding the selection of revascularization therapy are disease stability, procedural risk, patient comorbidities, atherosclerotic burden, and lesion complexity.

In general, $C A B G$ is preferred over percutaneous coronary intervention in patients with a heavy atherosclerotic burden and diabetes, and those without multiple significant baseline comorbidities, frailty, or short life expectancy.

CABG with arterial grafts can improve patient longevity, particularly with appropriate patient and coronary artery target selection.

Multiple arterial grafts should be considered over single thoracic artery and multiple vein conduits.

Less-invasive strategies are emerging.

Guideline-directed medical therapy in coronary artery disease is essential for improved outcomes in primary and secondary prevention.

doi:10.3949/ccjm.88a.20115
CORONARY ARTERY BYPASS GRAFTING (CABG) has been performed for more than 50 years. And even though the procedure is increasingly being used for older and higher-risk patients, outcomes have improved substantially over time. The surgery has developed beyond a "cookie-cutter" generic cardiac operation, and the use of a multidisciplinary, experienced heart team approach has become important.

This review briefly describes:

- The evolution of CABG

- Guidance for diagnosing coronary artery disease and determining the best strategy for intervention

- Conduit selection for CABG, including evidence supporting multiple arterial grafting

- The emergence of less-invasive strategies

- Enhanced recovery after surgery protocols

- The importance of medications.

\section{NEED FOR CABG IS GREAT}

Every year, about 18 million Americans are diagnosed with coronary artery disease, the most common cause of death in the United States. ${ }^{1}$ The estimated annual incidence of new myocardial infarctions is 720,000 , in addition to about 335,000 recurrent infarctions. ${ }^{1}$ Isolated $\mathrm{CABG}$ is the most common cardiac surgical procedure in North America. ${ }^{2}$

\section{EVOLUTION OF A SURGERY}

In 1968, Cleveland Clinic established CABG as the standard of care for obstructive coronary artery disease. ${ }^{3}$ Two years later, a Cleveland Clinic team led by René Favaloro ${ }^{4}$ reported on the workup and favorable outcomes of more than 300 patients who underwent "venous autograft reconstruction" with appropriate follow-up. ${ }^{4}$ 
All-venous-conduit CABG reigned from 1968 until January 1986, when Loop et $\mathrm{al}^{5}$ demonstrated improved graft patency and a 10 -year actuarial survival with internal thoracic artery (ITA) grafts compared with saphenous venous grafts anastomosed to the left anterior descending (LAD) coronary artery ( $86.6 \%$ vs $75.9 \%$ survival). The authors acknowledged that a randomized controlled trial would be beneficial to confirm their findings, but that this would not be possible because "present knowledge about late patency rates would bias the offering of the internal mammary [thoracic] artery and saphenous vein as comparable conduits in a trial." ${ }^{5}$ And they were right.

Pursuit of improved outcomes has intensified in the current era of public reporting. Perioperative mortality rates have been reported nationally at $2 \%$ (and at $<1 \%$ at some centers of excellence). ${ }^{3}$ But beyond perioperative mortality and morbidity, interest in improving long-term outcomes has grown. Debate continues about the use of bilateral ITA grafting and other multiarterial grafting strategies. Minimally invasive options and robotic assistance are also evolving. ${ }^{6}$ Given all

A multidisci-

plinary, experienced

heart team

approach

to CABG

is important these highly technical approaches requiring high-volume surgeon experience, some have recently called for coronary revascularization to be recognized as a subspecialty within cardiac surgery. ${ }^{7,8}$

\section{DIAGNOSTIC METHODS HAVE ADVANCED}

Coronary angiography remains the gold standard for diagnosing coronary artery disease. ${ }^{9}$ Optical coherence tomography, intravascular ultrasonography, fractional flow reserve, cardiac computed tomographic angiography, and cardiac magnetic resonance imaging (MRI) are newer diagnostic methods that provide more than a simple subjective visual estimation of coronary narrowing; they provide information on granular anatomic and physiologic features of coronary lesions and the downstream effect on the myocardium.

\section{Role of fractional flow reserve}

Stenosis seen by 2 -dimensional angiography does not always reflect a flow-limiting lesion. ${ }^{10}$ In fact, residual stenosis determined by coronary angiography does not affect outcomes if the patient is completely revascularized by fractional flow reserve criteria.

In the setting of percutaneous coronary intervention (PCI) in multivessel coronary artery disease, fractional flow reserve has been found to be superior to coronary angiography. Unfortunately, this has not been rigorously studied for surgical revascularization. ${ }^{10,11}$ Extrapolating the utility of fractional flow reserve to CABG entails the risk of erroneously downgrading a multivessel disease scenario or underestimating disease severity and forgoing CABG for a less invasive but also less durable therapy.

We have only limited data to correlate fractional flow reserve with graft patency. While venous grafts are not vulnerable to competitive flow from native coronary vessels, arterial grafts are at risk for failure when bypassing less-than-severe lesions. Compared with radial grafts, ITAs appear to be less vulnerable to competitive flow, with no clear stenosis cutoff and with excellent long-term patency rates even when used to bypass moderately diseased vessels. ${ }^{12}$ Radial grafts should only be used to bypass occluded or severely diseased vessels. ${ }^{13}$

\section{Cardiac MRI has evolved dramatically}

Late gadolinium enhancement cardiac MRI is a noninvasive nonstress test that has become the most sensitive and specific viability test. Image resolution is superior to that of singlephoton-emission computed tomography, and it identifies smaller, more distinct areas of fibrosis. Acutely, late gadolinium enhancement cardiac MRI can overestimate infarcts early due to tissue edema, but a transmural uptake of less than $50 \%$ infers functional improvement.

\section{TREATMENT CONSIDERATIONS}

Three main factors should be considered when deciding on an intervention strategy.

Disease stability. Stability of coronary artery disease and presentation-ie, ST-elevation myocardial infarction (STEMI), nonSTEMI, or stable angina-are factored into the management algorithm. PCI is the treatment of choice for STEMI; for non-STEMI and stable angina, recommendations are more nuanced. In patients with stable coronary artery disease and low-risk anatomic features, 
PCI has failed to show convincing evidence of benefit beyond a modest reduction in angina. ${ }^{14,15}$ Comparisons of CABG and medical therapy are dated, and emphasis now is on complementary rather than competing therapies. ${ }^{16,17}$ Medical treatments (eg, highintensity statins, dual antiplatelet therapy, angiotensin-converting enzyme inhibitors, angiotensin II receptor blockers, and novel glucose-lowering agents) are transforming primary and secondary cardiovascular prevention in patients with stable angina, resulting in reduced event rates in recent years. ${ }^{18} \mathrm{An}$ giotensin-converting enzyme inhibitors and angiotensin II receptor blockers for patients with type 2 diabetes mellitus and renal impairment are associated with reduced disease progression and recurrent ischemic events. ${ }^{19}$

Procedural risk and patient comorbidities. CABG risk is most commonly and reliably estimated by the Society of Thoracic Surgeons risk calculator, which estimates the risk of perioperative mortality and major morbidity. ${ }^{20}$ The latter includes stroke, with about a $1 \%$ perioperative rate, which is slightly higher than the risk associated with PCI. ${ }^{21}$ Advanced age is an important risk factor for stroke and periprocedural mortality, but it should be considered in the context of other risk factors when choosing between therapies.

Risk models perform well at a population level but are limited for estimating risk for individuals, particularly for patients with rare comorbidities (eg, cirrhosis) or unique risk profiles. Patients with significant baseline comorbidities, frailty (not captured by the Society of Thoracic Surgeons calculator), and reduced life expectancy are best suited for PCI.

Atherosclerotic burden and disease complexity. Coronary artery disease complexity is often assessed using the Synergy Between PCI With TAXUS and Cardiac Surgery (SYNTAX) trial score, ${ }^{22}$ which is incorporated in the American College of Cardiology-American Heart Association criteria for treatment selection. A heavy atherosclerotic burden favors $\mathrm{CABG}$ over PCI. ${ }^{23}$

\section{LEFT MAIN DISEASE}

Historically, the mortality rate in untreated left main coronary artery disease is about
$50 \%$ at 3 years. ${ }^{24}$ It is a heterogeneous condition that may involve the ostia, midshaft, bifurcation, or trifurcation. The specific areas involved affect the feasibility and success of PCI but have no bearing on CABG success or durability. The role of PCI vs CABG in left main disease is controversial, with 2 recent trials showing seemingly different findings. However, neither favored PCI over CABG. ${ }^{16}$

The 5-year Evaluation of XIENCE vs Coronary Artery Bypass Surgery for Effectiveness of Left Main Revascularization (EXCEL) trial showed noninferiority of PCI and CABG for left main disease, but an increased rate of allcause mortality with PCI at 5 years. ${ }^{25}$

The 5-year Nordic-Baltic-British Left Main Revascularization (NOBLE) trial, while not powered for mortality, showed that PCI was inferior to $\mathrm{CABG}$ for left main disease for reintervention and nonprocedural myocardial infarction, a marker of mortality. ${ }^{26}$

About $10 \%$ of STEMIs involve the left main coronary artery. In STEMI or hemodynamic instability, PCI is the treatment of choice. In non-STEMI and stable ischemia, the American College of Cardiology-American Heart Association guidelines give the highest recommendation for $\mathrm{CABG}$ for all SYNTAX levels (class I, level of evidence A $)^{27}$; PCI is recommended at this level only for low-risk SYNTAX scores.

\section{MULTIVESSEL DISEASE}

Left main and multivessel coronary artery disease are treated as different entities in the literature, even though less than $15 \%$ of lesions are isolated left main disease. SYNTAX 10. year data show an all-cause mortality benefit for CABG over PCI in patients with 3-vessel disease $(21 \%$ vs $28 \%){ }^{28}$

Current guidelines recommend CABG over PCI for multivessel coronary artery disease in patients with diabetes and for those with left ventricular dysfunction. ${ }^{27}$ Even for severe left ventricular dysfunction (ejection fraction $<35 \%$ ), CABG is associated with improved long-term outcomes, including survival, compared with PCI for patients with indications for $\mathrm{CABG}$ and who can tolerate the stress of surgery. ${ }^{29}$

Why CABG improves outcomes for left
Isolated CABG is the most common cardiac surgical procedure in North America 
main and multivessel coronary artery disease is likely multifactorial. The distal insertion of a bypass graft is downstream from where most future atherosclerotic disease might develop. In addition, use of arterial grafts that are resistant to atherosclerosis enhances long-term patency. Data suggest that the incremental benefit of CABG is strongly associated with the use of the ITA. ${ }^{30}$ Finally, surgical revascularization more frequently achieves complete revascularization, which is associated with improved survival.

\section{CONDUIT SELECTION FOR CABG}

Conduit selection is a current topic of debate.

Saphenous vein. Attrition of the saphenous vein graft, the Achilles' heel of CABG, occurs in phases. The first phase is nearly immediate and likely related to a technical factor. This can be avoided with intraoperative evaluation of the bypass graft. Transit-time flow meters can identify low graft flows due to thrombosis, kinking, conduit dissection, coronary dissection, or anastomosis stenosis, all of which are potentially correctable. ${ }^{31}$ Subsequent phases of vein graft failure include in-

Stenosis seen by 2-dimensional angiography does not always reflect a flow-limiting lesion timal hyperplasia and atherosclerosis. Saphenous vein graft attrition rates of $1 \%$ to $2 \%$ per year for the first 6 years and $4 \%$ per year for the next decade have been reported..$^{32}$

Arteries vs veins. Dimitrova et $\mathrm{al}^{33}$ reported that angiography over a 15 -year period revealed that coronary territories bypassed with arteries had less disease progression compared with territories bypassed with veins. The internal elastic lamina of arterial grafts protects them from disease progression. Native coronary disease is also protected by arterial grafts for unclear reasons, but possibly due to the downstream effect of vasoactive signals. ${ }^{34}$

ITA and radial artery grafts. At 15 years, right ITA graft patency is reported to be more than $90 \%$ and left ITA graft patency more than 95\%. ${ }^{35}$ The Society of Thoracic Surgeons guidelines ${ }^{13}$ recommend the following:

- ITA grafts should be used to bypass the LAD artery when bypass of the LAD artery is indicated (class of recommendation [COR] I, level of evidence [LOE] B)

- As an adjunct to a left ITA graft, a second arterial graft (right ITA or radial artery) should be considered in appropriate patients (COR Ila, LOE B)

- Use of arterial grafts (including specific targets, number, and type) should be a part of the discussion of the heart team in determining the optimal approach for each patient (COR I, LOE C).

In 2019, RADIAL study 5-year data showed a benefit for using the radial artery rather than the saphenous vein for graft occlusion and target revascularization. ${ }^{36}$ Rates of myocardial infarction and repeat revascularization were also superior for radial arteries, and a mortality benefit was reported in a follow-up study. ${ }^{37}$

\section{SINGLE VS MULTIPLE ARTERIAL GRAFTING}

\section{Evidence favors multiarterial options}

In 2019, the Arterial Revascularization Trial (ART) 10-year intention-to-treat data showed no difference in survival or event-free survival for bilateral vs left ITA. However, a $14 \%$ crossover rate, excellent medical compliance, and a radial artery conduit in more than $20 \%$ of patients possibly clouded the results. ${ }^{38} \mathrm{~A}$ post hoc as-treated analysis showed improved mortality and major adverse cardiac and cerebrovascular events with multiple arterial grafting. Additionally, a 5-year post hoc analysis found that radial artery grafting improved outcomes in both groups. ${ }^{39}$

Since 2001, 5 major systematic reviews and 1 meta-analysis found that bilateral ITA grafting offered a survival advantage over left ITA grafting, including long-term survival, reduced hospital mortality, reduced cerebrovascular accidents, and reduced revascularization. $^{38}$

Despite evidence of the benefits of multiple arterial grafting and the professional association recommendations to encourage its use, only a small percentage of patients undergoing CABG in the United States receive multiarterial grafts. Reasons for this include additional technical complexity, prolonged operative times, and potential for complications. ${ }^{40}$

\section{Regional practice differences}

In California, receipt of a second arterial graft decreased from $10.7 \%$ of isolated CABG operations in 2006 to $9.1 \%$ in 2011, with the use of a radial artery graft falling from $7.8 \%$ 
to $6.6 \%$ and a right ITA graft from $3.0 \%$ to $2.4 \% .{ }^{41}$ Despite these trends, there is a clear survival advantage for multiarterial grafting 7 years after surgery.

Chikwe et $\mathrm{al}^{42}$ performed a retrospective cohort analysis with propensity matching. Of patients undergoing CABG between 2005 and 2012, 14\% received multiarterial grafting, a nearly $50 \%$ higher rate than was found in the California study. Patients receiving multiarterial grafts were younger and healthier at baseline. After propensity matching, those receiving multiarterial grafts had better 10 -year survival and lower 10-year myocardial infarction and reintervention rates. However, the study also identified subgroups of patients, including those with advanced age or renal disease, who might not realize additional benefits from multiarterial grafting.

\section{Ongoing trial may provide standard}

The ongoing Randomization of Single vs Multiple Arterial Grafts (ROMA) trial is expected to be the definitive prospective randomized trial comparing multiple arterial grafting vs a single ITA to the LAD artery with saphenous vein graft bypasses to the remaining targets. ${ }^{43}$ The enrollment goal is 4,300 patients, and the composite outcomes include death, stroke, myocardial infarction, and repeat revascularization.

\section{Optimizing success of multiarterial grafts}

Multiple arterial grafting (Figure 1) is not without its nuances, including conduit choice and intended target coronary vessel. For example, radial artery grafts are best used to bypass severely diseased target vessels to minimize competitive flow and optimize graft patency..$^{13}$ The myocardial mass supplied by a diseased vessel is also critically important. Important target vessels extend more than $75 \%$ of the way to the apex of the heart. Matching important vessels (extending more than $75 \%$ to the apex) with the second arterial graft has a long-term mortality benefit. ${ }^{44}$

The feared risk of sternal wound complications associated with bilateral ITA harvesting can be mitigated by meticulous harvesting techniques and ITA skeletonization. ${ }^{45}$ Skeletonization separates the ITA from adjacent tissues, with the surgeon staying close to the ITA wall throughout the dissection, thereby

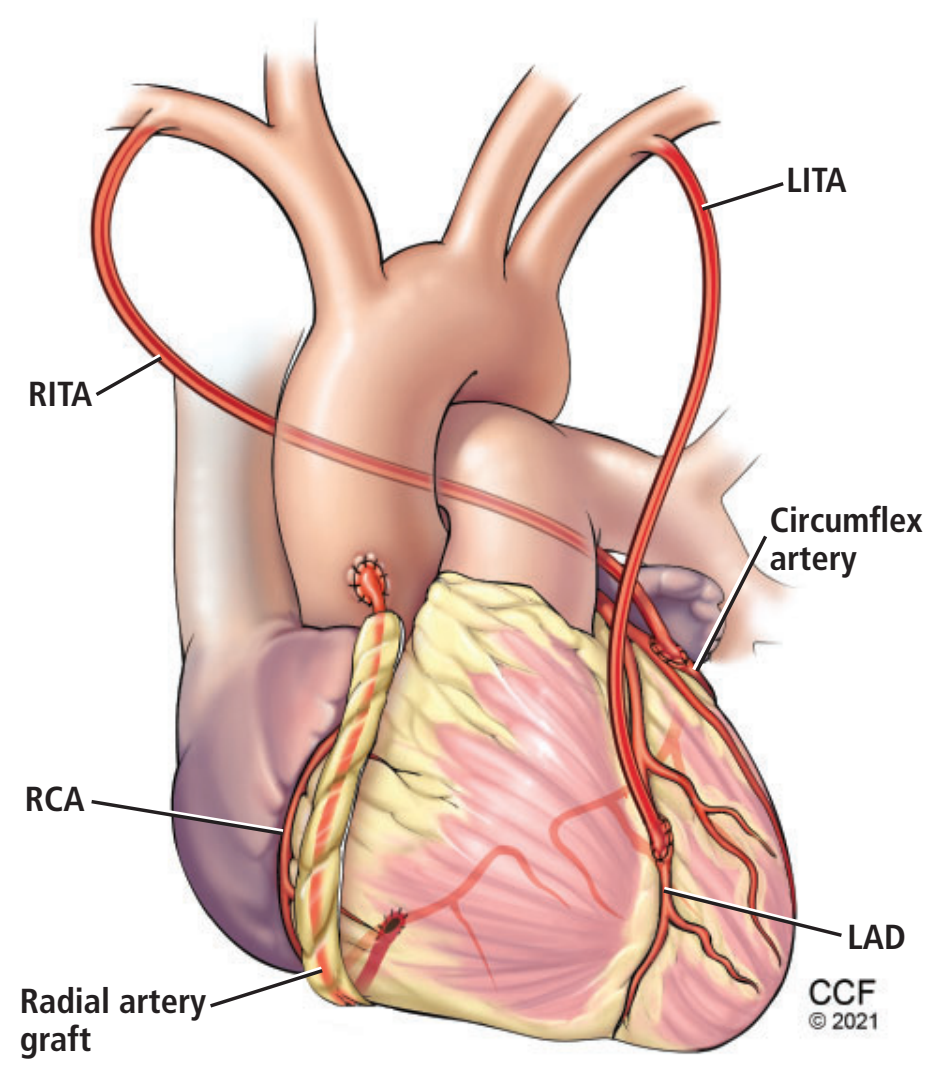

Figure 1. An example of multiarterial coronary artery bypass grafting. The left internal thoracic artery (LITA) is used to bypass the left anterior descending artery (LAD), the right internal thoracic artery (RITA) to bypass the circumflex artery, and the radial artery to bypass the right coronary artery (RCA).

reducing adjacent tissue damage and preserving collateral routes of blood flow to the sternum compared with techniques that take the ITA as a pedicle that incorporates adjacent chest wall tissues. There is a theoretical risk of increased ITA injury in the hands of inexperienced harvesters, but data on the differential patency rates between skeletonized vs pedicled ITAs are limited.

The importance of an experienced coronary surgeon in decision-making and the performance of CABG cannot be overstated. ${ }^{7,8}$ A specific volume-outcome relationship has been described for bilateral ITA grafting. ${ }^{46}$ The increased risk associated with surgery for complex revascularization procedures such as redo CABG is well documented ${ }^{47}$ but is mitigated by surgical expertise. ${ }^{48}$ In addition, a focused interest in CABG facilitates innova- 


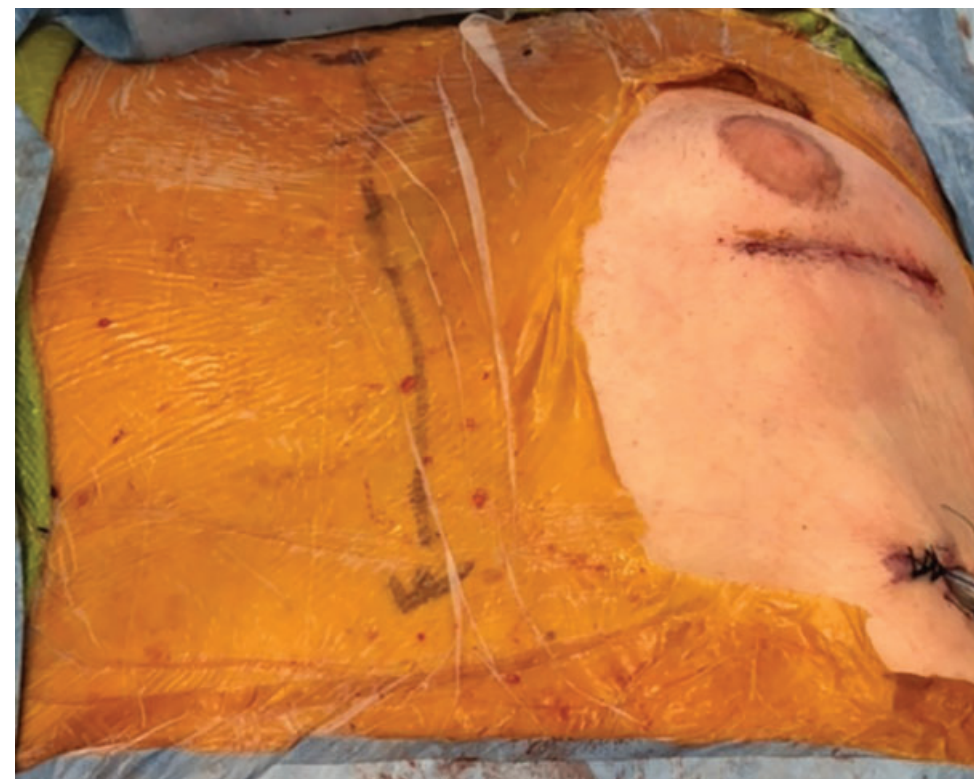

Figure 2. Example of minimally invasive coronary artery bypass grafting, performed through a small left thoracotomy incision, in which the left internal thoracic artery is bypassed to the left anterior descending artery without use of a heart-lung machine. The patient's head is toward the top, and the skin marking is where a traditional sternotomy incision is placed.

Opioid-sparing
techniques are
improving
outcomes
and decreasing
length of stay;
minimizing
opioid use
also reduces
the incidence
of delirium

tion and the development of less invasive approaches.

\section{LESS-INVASIVE CABG STRATEGIES}

Off-pump CABG avoids use of cardiopulmonary bypass and is physiologically less invasive than traditional on-pump CABG. Off-pump CABG can benefit select high-risk patients not typically enrolled in trials. Surgical experience is critical in mitigating reduced graft patency and incomplete revascularization associated with off-pump CABG. ${ }^{49}$ Widespread adoption is ill-advised, and indeed, use of offpump CABG has declined.

Robotic CABG accounts for less than $1 \%$ of CABG operations in the United States. ${ }^{6}$ Data supporting use of these procedures outside of select specialized centers are currently limited. Technology is lagging, and it is difficult to teach robotic multiarterial CABG and reliably achieve complete revascularization.

Hybrid CABG uses robotic or minimally invasive left ITA harvest with a direct handsewn left ITA-to-LAD artery anastomosis through a minithoracotomy (Figure 2). Non-
LAD artery stenosis is then addressed with drug-eluting stents. Theoretical benefits are lower occurrence of stroke, decreased infection, sternal sparing, fewer transfusions, and faster recovery. The Safety and Efficacy of Hybrid Revascularization in Multivessel Coronary Artery Disease study (POL-MIDES) found no difference between traditional and hybrid CABG in outcomes at 1 and 5 years. ${ }^{6}$ Other trials are ongoing, and more are expected in the future.

\section{OPTIMIZING RECOVERY AFTER SURGERY}

Enhanced recovery after surgery relies on evidence-based protocols designed to improve outcomes and cost-savings based on rigorous data review and protocol development. ${ }^{50}$ Postoperative goal-directed hemodynamic resuscitation algorithms reduce 30-day major adverse cardiovascular events in high-risk patients. ${ }^{51}$ Similarly, fast-track early extubation protocols decrease time on a ventilator. Shorter extubation times are associated with decreased length of stay and hospital cost. ${ }^{52}$

\section{Opioid-sparing pain management}

In this era of opioid abuse, pain management has come under global public scrutiny. More importantly, opioid-sparing techniques are improving patient outcomes and decreasing length of stay. Minimizing opioid use also reduces the incidence of delirium. Some form of delirium can occur in nearly $50 \%$ of postoperative cardiac surgery patients, increasing hospital mortality and readmission and decreasing long-term survival..$^{50}$ Many causes of delirium are reversible, and frequent delirium screening by bedside nurses and critical care teams improves outcomes.

\section{Glycemic control}

Multiple mechanisms to deal with postoperative complications secondary to hyperglycemia exist. Goal blood glucose levels of 80 to $110 \mathrm{mg} / \mathrm{dL}$ are well established. ${ }^{53}$ Glucose levels over 160 to $180 \mathrm{mg} / \mathrm{dL}$ managed with insulin infusions have improved outcomes, including reduced infections.

\section{SECONDARY PREVENTION}

Optimal medical management for secondary prevention and improved long-term outcomes 
after CABG has been increasingly recognized. ${ }^{54}$ Discharge prescriptions for beta blockers and statins are process measures tracked by the Society of Thoracic Surgeons as part of its program quality ratings. The benefits of beta blockers include a potential decrease in long-term mortality after CABG. ${ }^{55}$ In patients receiving radial artery grafting, use of antispasmodic medications, including calcium channel blockers, is associated with improved outcomes. ${ }^{56}$ Statin use after surgery is associated with decreased readmissions and late death from myocardial infarction or stroke. ${ }^{57}$

Dual antiplatelet therapy is now recommended for 6 months in patients with acute coronary syndrome undergoing CABG. Additionally, in patients who had coronary stenting prior to $\mathrm{CABG}$, dual antiplatelet therapy may prolong stent patency and prevent thrombus development and propagation. ${ }^{58}$

Comprehensive rehabilitation programs have been developed to prevent readmissions and improve treatment compliance and quality of life after discharge. Medication adherence dramatically improves outcomes regardless of coronary revascularization strategy. ${ }^{59}$ For patients who do not adhere to medications, CABG leads to improved major cardiac eventfree survival. New methods of improving treatment adherence are currently being evaluated; they include wearable technology, educational tools, and increased use of virtual visits.

\section{DISCLOSURES}

The authors report no relevant financial relationships which, in the context of their contributions, could be perceived as a potential conflict of interest.

\section{REFERENCES}

1. Virani SS, Alonso A, Benjamin EJ, et al. Heart disease and stroke statistics-2020 update: a report from the American Heart Association. Circulation 2020; 141(9):e139-e596. doi:10.1161/CIR.0000000000000757

2. D'Agostino RS, Jacobs JP, Badhwar V, et al. The Society of Thoracic Surgeons adult cardiac surgery database: 2019 update on outcomes and quality. Ann Thorac Surg 2019; 107(1):24-32. doi:10.1016/j. athoracsur.2018.10.004

3. Bakaeen FG, Blackstone EH, Pettersson GB, Gillinov AM, Svensson LG. The father of coronary artery bypass grafting: René Favaloro and the 50th anniversary of coronary artery bypass grafting. J Thorac Cardiovasc Surg 2018; 155(6):2324-2328. doi:10.1016/j.jtcvs.2017.09.167

4. Sheldon WC, Favaloro RG, Sones FM Jr, Effler DB. Reconstructive coronary artery surgery. Venous autograft technique. JAMA 1970; 213(1):78-82. pmid:5467974

5. Loop FD, Lytle BW, Cosgrove DM, et al. Influence of the internalmammary-artery graft on 10-year survival and other cardiac events. N Engl J Med 1986; 314(1):1-6. doi:10.1056/NEJM198601023140101

6. Gaudino M, Bakaeen F, Davierwala P, et al. New strategies for surgical myocardial revascularization. Circulation 2018; 138(19):21602168. doi:10.1161/CIRCULATIONAHA.118.035956

7. Bakaeen FG, Johnston DR, Svensson LG. Commentary: coronary artery bypass grafting as a subspecialty: hype or reality. J Thorac Cardiovasc Surg 2020; S0022-5223(20)30903-X. April 18, 2020. doi:10.1016/j.jtcvs.2020.04.013

8. Rosati CM, Torregrossa G, Balkhy HH, Puskas JD. Dedicated training in advanced coronary surgery: need and opportunity. J Thorac Cardiovasc Surg 2020; S0022-5223(20)30906-5. April 18, 2020. doi:10.1016/j.jtcvs.2020.03.152

9. Sones FM Jr, Shirey EK, Proudfit WL, Westcott RN. Cine-coronary arteriography. Circulation 1959; 20:773-774.

10. Tonino PA, De Bruyne B, Pijls NH, et al. Fractional flow reserve versus angiography for guiding percutaneous coronary intervention. $\mathrm{N}$ Engl J Med 2009; 360(3):213-224. doi:10.1056/NEJMoa0807611

11. Omer S, Bakaeen FG. Commentary: setting priorities in coronary artery bypass grafting: do what you can when you can-as long as it's arterial. J Thorac Cardiovasc Surg 2019; S0022-5223(19)37095-3. Published December 14, 2019. doi:10.1016/j.jtcvs.2019.11.111

12. Raza S, Blackstone EH, Houghtaling PL, et al. Natural history of moderate coronary artery stenosis after surgical revascularization.
Ann Thorac Surg 2018; 105(3):815-821.

doi:10.1016/j.athoracsur.2017.08.053

13. Aldea GS, Bakaeen FG, Pal J, et al. The Society of Thoracic Surgeons clinical practice guidelines on arterial conduits for coronary artery bypass grafting. Ann Thorac Surg 2016; 101(2):801-809. doi:10.1016/j.athoracsur.2015.09.100

14. Boden WE, O'Rourke RA, Teo KK, et al. Optimal medical therapy with or without PCI for stable coronary disease. N Engl J Med 2007; 356(15):1503-1516. doi:10.1056/NEJMoa070829

15. Maron DJ, Hochman JS, Reynolds HR, et al. Initial invasive or conservative strategy for stable coronary disease. N Engl J Med 2020; 382(15):1395-1407. doi:10.1056/NEJMoa1915922

16. Tam DY, Bakaeen F, Feldman DN, et al. Modality selection for the revascularization of left main disease. Can J Cardiol 2019; 35(8):983992. doi:10.1016/j.cjca.2018.12.017

17. Yusuf S, Zucker D, Peduzzi P, et al. Effect of coronary artery bypass graft surgery on survival: overview of 10-year results from randomised trials by the Coronary Artery Bypass Graft Surgery Trialists Collaboration. Lancet 1994; 344(8922):563-570. doi:10.1016/s0140-6736(94)91963-1

18. Arnold SV, Bhatt DL, Barsness GW, et al. Clinical management of stable coronary artery disease in patients with type 2 diabetes mellitus: a scientific statement from the American Heart Association. Circulation 2020; 141(19):e779-e806. doi:10.1161/CIR.0000000000000766

19. Heart Outcomes Prevention Evaluation Study Investigators. Effects of ramipril on cardiovascular and microvascular outcomes in people with diabetes mellitus: results of the HOPE study and MICRO-HOPE substudy. Lancet 2000; 355(9200):253-259. pmid:10675071

20. O'Brien SM, Feng L, He X, et al. The Society of Thoracic Surgeons 2018 adult cardiac surgery risk models: part 2-statistical methods and results. Ann Thorac Surg 2018; 105(5):1419-1428. doi:10.1016/j.athoracsur.2018.03.003

21. Gaudino M, Benesch C, Bakaeen F, et al. Considerations for reduction of risk of perioperative stroke in adult patients undergoing car diac and thoracic aortic operations: a scientific statement from the American Heart Association. Circulation 2020; 142(14):e193-e209. doi:10.1161/CIR.0000000000000885

22. Head SJ, Milojevic M, Daemen J, et al. Mortality after coronary artery bypass grafting versus percutaneous coronary intervention with stenting for coronary artery disease: a pooled analysis of individual patient data. Lancet 2018; 391(10124):939-948. doi:10.1016/S0140-6736(18)30423-9 
23. Patel MR, Calhoon JH, Dehmer GJ, et al. ACC/AATS/AHA/ASE/ASNC/ SCAI/SCCT/STS 2017 appropriate use criteria for coronary revascularization in patients with stable ischemic heart disease: a report of the American College of Cardiology Appropriate Use Criteria Task Force, American Association for Thoracic Surgery, American Heart Association, American Society of Echocardiography, American Society of Nuclear Cardiology, Society for Cardiovascular Angiography and Interventions, Society of Cardiovascular Computed Tomography, and Society of Thoracic Surgeons. J Am Coll Cardiol 2017; 69(17):22122241. doi:10.1016/j.jacc.2017.02.001

24. Collet C, Capodanno D, Onuma Y, et al. Left main coronary artery disease: pathophysiology, diagnosis, and treatment. Nat Rev Cardiol 2018; 15(6):321-331. doi:10.1038/s41569-018-0001-4

25. Giustino G, Serruys PW, Sabik JF 3rd, et al. Mortality after repeat revascularization following $\mathrm{PCI}$ or CABG for left main disease: the EXCEL trial. JACC Cardiovasc Interv 2020; 13(3):375-387. doi: 10.1016/j.jcin.2019.09.019

26. Holm NR, Mäkikallio T, Lindsay MM, et al; NOBLE investigators. Percutaneous coronary angioplasty versus coronary artery bypass grafting in the treatment of unprotected left main stenosis: updated 5-year outcomes from the randomised, non-inferiority NOBLE trial. Lancet 2020; 395(10219):191-199.

doi:10.1016/S0140-6736(19)32972-1

27. Hillis LD, Smith PK, Anderson JL, et al. 2011 ACCF/AHA guideline for coronary artery bypass graft surgery. A report of the American College of Cardiology Foundation/American Heart Association Task Force on Practice Guidelines. Developed in collaboration with the American Association for Thoracic Surgery, Society of Cardiovascular Anesthesiologists, and Society of Thoracic Surgeons. J Am Coll Cardiol 2011; 58(24):e123-e210. doi:10.1016/j.jacc.2011.08.009

28. Thuijs DJFM, Kappetein AP, Serruys PW, et al. Percutaneous coronary intervention versus coronary artery bypass grafting in patients with three-vessel or left main coronary artery disease: 10-year follow-up of the multicentre randomised controlled SYNTAX trial. Lancet 2019; 394(10206):1325-1334. doi:10.1016/S0140-6736(19)31997-X

29. Sun LY, Gaudino M, Chen RJ, Bader Eddeen A, Ruel M. Long-term outcomes in patients with severely reduced left ventricular ejection fraction undergoing percutaneous coronary intervention vs coronary artery bypass grafting. JAMA Cardiol 2020; 5(6):631-641. doi:10.1001/jamacardio.2020.0239

30. Influence of diabetes on 5-year mortality and morbidity in a randomized trial comparing CABG and PTCA in patients with multivessel disease: the Bypass Angioplasty Revascularization Investigation (BARI). Circulation 1997; 96(6):1761-1769.

doi:10.1161/01.cir.96.6.1761

31. D'Ancona G, Karamanoukian HL, Ricci M, Schmid S, Bergsland J, Salerno TA. Graft revision after transit time flow measurement in off-pump coronary artery bypass grafting. Eur J Cardiothorac Surg 2000; 17(3):287-293. doi:10.1016/s1010-7940(00)00332-8

32. Fitzgibbon GM, Kafka HP, Leach AJ, Keon WJ, Hooper GD, Burton JR. Coronary bypass graft fate and patient outcome: angiographic follow-up of 5,065 grafts related to survival and reoperation in 1,388 patients during 25 years. J Am Coll Cardiol 1996; 28(3):616626. doi:10.1016/0735-1097(96)00206-9

33. Dimitrova KR, Hoffman DM, Geller CM, Dincheva G, Ko W Tranbaugh RF. Arterial grafts protect the native coronary vessels from atherosclerotic disease progression. Ann Thorac Surg 2012; 94(2):475-481. doi:10.1016/j.athoracsur.2012.04.035

34. Lüscher TF, Diederich $D$, Siebenmann $R$, et al. Difference between endothelium-dependent relaxation in arterial and in venous coronary bypass grafts. N Engl J Med 1988; 319(8):462-467. doi:10.1056/NEJM198808253190802

35. Lytle BW, Blackstone EH, Sabik JF, Houghtaling P, Loop FD, Cosgrove DM. The effect of bilateral internal thoracic artery grafting on survival during 20 postoperative years. Ann Thorac Surg 2004; 78(6):2005-2014. doi:10.1016/j.athoracsur.2004.05.070

36. Gaudino M, Benedetto U, Fremes S, et al. Radial-artery or saphenous-vein grafts in coronary-artery bypass surgery. N Engl J Med 2018; 378(22):2069-2077. doi:10.1056/NEJMoa1716026
37. Gaudino M, Benedetto U, Fremes S, et al. Association of radial artery graft vs saphenous vein graft with long-term cardiovascular outcomes among patients undergoing coronary artery bypass grafting: a systematic review and meta-analysis. JAMA 2020; 324(2):179187. doi:10.1001/jama.2020.8228

38. Gaudino M, Bakaeen FG, Benedetto U, et al. Arterial grafts for coronary bypass: a critical review after the publication of ART and RADIAL. Circulation 2019; 140(15):1273-1284. doi:10.1161/CIRCULATIONAHA.119.041096

39. Taggart DP, Altman DG, Flather M, et al. Associations between adding a radial artery graft to single and bilateral internal thoracic artery grafts and outcomes: insights from the Arterial Revascularization Trial. Circulation 2017; 136(5):454-463. doi:10.1161/CIRCULATIONAHA.117.027659

40. Bakaeen FG, Svensson LG. Why don't we kill 2 birds with 1 stone? Less adverse cardiac events and improved survival with multiarterial coronary artery bypass grafting. Circulation 2018; 137(16):17081711. doi:10.1161/CIRCULATIONAHA.117.032885

41. Goldstone $A B$, Chiu P, Baiocchi $M$, et al. Second arterial versus venous conduits for multivessel coronary artery bypass surgery in California. Circulation 2018; 137(16):1698-1707. doi:10.1161/CIRCULATIONAHA.117.030959

42. Chikwe J, Sun E, Hannan EL, et al. Outcomes of second arterial conduits in patients undergoing multivessel coronary artery bypass graft surgery. J Am Coll Cardiol 2019; 74(18):2238-2248. doi:10.1016/j.jacc.2019.08.1043

43. Gaudino M, Alexander JH, Bakaeen FG, et al. Randomized comparison of the clinical outcome of single versus multiple arterial grafts: the ROMA trial-rationale and study protocol. Eur J Cardiothorac Surg 2017; 52(6):1031-1040. doi:10.1093/ejcts/ezx358

44. Bakaeen FG, Ravichandren K, Blackstone EH, et al. Coronary artery target selection and survival after bilateral internal thoracic artery grafting. J Am Coll Cardiol 2020; 75(3):258-268. doi:10.1016/j.jacc.2019.11.026

45. Benedetto U, Altman DG, Gerry S, et al. Pedicled and skeletonized single and bilateral internal thoracic artery grafts and the incidence of sternal wound complications: Insights from the Arterial Revascularization Trial. J Thorac Cardiovasc Surg 2016; 152(1):270-276. doi:10.1016/j.jtcvs.2016.03.056

46. Gaudino M, Bakaeen F, Benedetto U, et al. Use rate and outcome in bilateral internal thoracic artery grafting: insights from a systematic review and meta-analysis. J Am Heart Assoc 2018; 7(11):e009361. doi:10.1161/JAHA.118.009361

47. Elbadawi A, Hamed M, Elgendy IY, et al. Outcomes of reoperative coronary artery bypass graft surgery in the United States. J Am Heart Assoc 2020; 9(15):e016282. doi:10.1161/JAHA.120.016282

48. Sabik JF 3rd, Blackstone EH, Houghtaling PL, Walts PA, Lytle BW. Is reoperation still a risk factor in coronary artery bypass surgery? Ann Thorac Surg 2005; 80(5):1719-1727. doi:10.1016/j.athoracsur.2005.04.033

49. Patel V, Unai S, Gaudino M, Bakaeen F. Current readings on outcomes after off-pump coronary artery bypass grafting. Semin Thorac Cardiovasc Surg 2019; 31(4):726-733. doi:10.1053/j.semtcvs.2019.05.012

50. Engelman DT, Ben Ali W, Williams JB, et al. Guidelines for perioperative care in cardiac surgery: Enhanced Recovery After Surgery society recommendations. JAMA Surg 2019; 154(8):755-766. doi:10.1001/jamasurg.2019.1153

51. Osawa EA, Rhodes A, Landoni G, et al. Effect of perioperative goaldirected hemodynamic resuscitation therapy on outcomes following cardiac surgery: a randomized clinical trial and systematic review. Crit Care Med 2016; 44(4):724-733. doi:10.1097/CCM.0000000000001479

52. Meade MO, Guyatt G, Butler R, et al. Trials comparing early vs late extubation following cardiovascular surgery. Chest 2001; 120 (6 suppl):445S-453S. doi:10.1378/chest.120.6_suppl.445s

53. Lazar HL, Chipkin SR, Fitzgerald CA, Bao Y, Cabral H, Apstein CS. Tight glycemic control in diabetic coronary artery bypass graft patients improves perioperative outcomes and decreases 


\section{DIMELING AND COLLEAGUES}

recurrent ischemic events. Circulation 2004; 109(12):1497-1502. doi:10.1161/01.CIR.0000121747.71054.79

54. Kulik A, Ruel M, Jneid $H$, et al. Secondary prevention after coronary artery bypass graft surgery: a scientific statement from the American Heart Association. Circulation 2015; 131(10):927-964. doi:10.1161/CIR.0000000000000182

55. Zhang $H$, Yuan $X$, Zhang $H$, et al. Efficacy of long-term $\beta$-blocker therapy for secondary prevention of long-term outcomes after coronary artery bypass grafting surgery. Circulation 2015; 131(25):21942201. doi:10.1161/CIRCULATIONAHA.114.014209

56. Gaudino M, Benedetto U, Fremes SE, et al. Effect of calcium-channel blocker therapy on radial artery grafts after coronary bypass surgery. J Am Coll Cardiol 2019; 73(18):2299-2306. doi:10.1016/j.jacc.2019.02.054
57. Shau WY, Lai CL, Huang ST, et al. Statin adherence and persistence on secondary prevention of cardiovascular disease in Taiwan. Heart Asia 2019; 11(2):e011176. doi:10.1136/heartasia-2018-011176

58. Levine GN, Bakaeen FG. Adding CABG to the dual antiplatelet salad. J Am Coll Cardiol 2017; 69(2):128-130. doi:10.1016/j.jacc.2016.10.040

59. Kurlansky $\mathbf{P}$, Herbert M, Prince $S$, Mack M. Coronary artery bypass graft versus percutaneous coronary intervention: meds matter: impact of adherence to medical therapy on comparative outcomes. Circulation 2016; 134(17):1238-1246. doi:10.1161/CIRCULATIONAHA.115.021183

Address: Faisal G. Bakaeen, MD, FACS, Department of Thoracic and Cardiovascular Surgery, J4-1, Cleveland Clinic, 9500 Euclid Avenue, Cleveland, OH 44195; bakaeef@ccf.org 